\title{
Purification and Characterization of the Polysaccharide Obtained from Squid Internal Shell*1
}

\author{
Koichi OKutani*2 and Nobuo MorikaWa*2
}

(Received January 13, 1978)

\begin{abstract}
Polysaccharides A and B were isolated in pure form from the squid internal shell. The purification of the polysaccharide was carried out by using DEAE-cellulose column chromatography. These purified products were homogeneous when examined by gel-filtrations and ultracentrifugations.

The distribution constant values $\left(K_{d}\right)$ of these purified polysaccharides, calculated by the Sepharose 4B column chromatography, were $K_{d}=0.90$ for polysaccharide A and $K_{d}=0.79$ for polysaccharide B. Approximate sedimentation coefficients were $1.96 \mathrm{~S}$ for polysaccharide A and $3.20 \mathrm{~S}$ for polysaccharide $B$. The infrared spectra of these purified polysaccharides $A$ and $B$ likewise indicated the presence of $\beta$-linkages $\left(890 \mathrm{~cm}^{-1}\right)$. Both polysaccharides were composed of glucose as the sole constituent monosaccharide.
\end{abstract}

In the preceding paper, ${ }^{11}$ we reported the isolation procedure and the molecular weight distribution of the polysaccharide fraction from squid internal shell.

It has been shown that the polysaccharide contains residues of L-arabinose, L-rhamnose, Dxylose, D-mannose, D-galactose, D-glucose, Dglucosamine and D-galactosamine as constituent monosaccharides.

In the present experiments, a method is described for the isolation of homogeneous polysaccharides from squid internal shell using DEAEcellulose column chromatography.

Purified polysaccharides prepared by this method were then characterized as to its physical and chemical composition.

\section{Materials and Methods}

\section{Preparation of the Crude Extract}

The crude polysaccharide extract was prepared from acetone-extracted squid internal shell by treatment with $0.01 \mathrm{M}$-EDTA solution as described in the previous paper. ${ }^{1-2\}}$

\section{Ion-Exchange and Gel-Filtration Chromatographies \\ Ion-exchange chromatography was carried out on a column of DEAE-cellulose (Serva) and eluted with a stepwise gradient of $\mathrm{NaCl}$.}

Gel-filtration was done by using Sepharose 4B (Pharmacia). Elution was carried out with $0.5 \mathrm{M}$ $\mathrm{NaCl}$ solution. Void volume $\left(V_{0}\right)$ and total volume $\left(V_{t},=V_{0}+\right.$ internal volume) of the column were estimated with blue dextran 2000 and urocanic acid respectively.

Fractions of eluate were analyzed, as necessary, for total carbohydrate and protein. Total carbohydrate was determined by phenol-sulphuric acid method (OD at $490 \mathrm{~nm}$ ). Protein was determined by the UV absorption method (OD at 280 $\mathrm{nm}$ ).

\section{Elementary Analysis}

The determinations of $\mathrm{C}, \mathrm{H}$ and $\mathrm{N}$ were carried out by using $\mathrm{CHN}$ corder (Yanagimoto model MT-2).

\section{Ultracentrifugal Analysis}

Solution for ultracentrifugal characterization was prepared by dissolving purified polysaccharide in $0.1 \mathrm{M}-\mathrm{NaCl}$ solution. Sedimentation pattern was made on this solution with a Hitachi model 282 analytical ultracentrifuge.

\section{Infrared Spectrum (IR)}

The IR spectrum was obtained using the $\mathrm{KBr}$ pellet technique in a Hitachi model EPI-G2 spectrometer.

\section{Monosaccharide Analysis}

After the polysaccharide was hydrolyzed with

*1 An Antitumor Substance Obtained from the Internal Shell of Squid-II.

*1 Contribution No. 14 from the Marine Biological Station, Faculty of Agriculture, Kagawa University

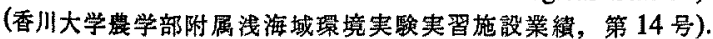

*2 Faculty of Agriculture, Kagawa University, Kagawa 761-07 Japan (奥谷康一·森川演夫：香川大学啀学部). 
$2 \mathrm{~N}-\mathrm{HCl}$ and methanolyzed with $5 \%$ methanol$\mathrm{HCl}$, the constituent monosaccharides were analyzed with GLC as described in the previous paper. ${ }^{11}$

\section{Gas Chromatography (GLC)}

Analysis was performed with a Nihon Denshi model JGC-750 equipped with dual flame ionization detectors, using stainless steel columns $(0.3 \times 300 \mathrm{~cm})$, packed with $3 \%$ OV-17 on 80 100 mesh Shimalite (Shimazu). The carrier gas was nitrogen. Sample was introduced at $100^{\circ} \mathrm{C}$ and the temperature was held for $2 \mathrm{~min}$. The column temperature was programed to rise to a maximum of $230^{\circ} \mathrm{C}$ at a rate of $6^{\circ} \mathrm{C} / \mathrm{min}$ after the hold interval. The final temperature was maintained until all peaks were eluted.

\section{Results and Discussion}

The fractionation of the crude extract on DEAE-cellulose $\left(\mathrm{Cl}^{-}\right)$was shown in Fig. 1. Three major peaks of the polysaccharide were separated. These peaks were pooled in three fractions (Fraction I, II and III) which were eluted with $0.01,0.1$ and $0.5 \mathrm{M}-\mathrm{NaCl}$ solutions respectively. These pools were complex mixtures of polysaccharides and were further fractionated by DEAE-cellulose $\left(\mathrm{OH}^{-}\right)$column chromatography. Studies on Fraction-I were described in the present paper.

Fraction-I gave two peaks on DEAE-cellulose $\left(\mathrm{OH}^{-}\right)$column chromatography (Fig. 2). The first peak (polysaccharide $\mathrm{A}$ ) was eluted with water

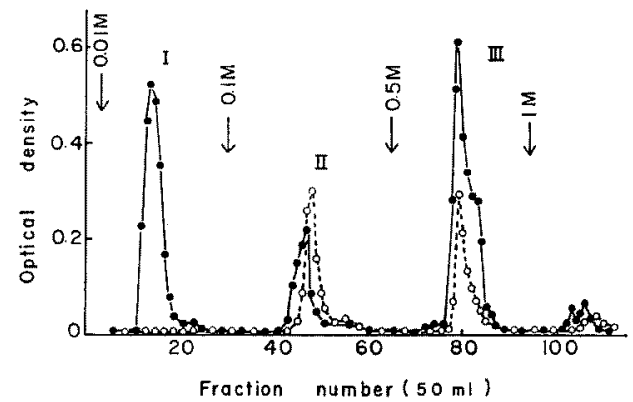

Fig. 1. DEAE-cellulose column chromatography of the crude extract.

The crude extract $(327 \mathrm{mg}$ ) was dissolved in $100 \mathrm{~m} l$ of $0.01 \mathrm{M}-\mathrm{NaCl}$ solution and applied to a column $(3.8 \times 80 \mathrm{~cm})$ of DEAE-cellulose $\left(\mathrm{Cl}^{-}\right)$equilibrated with $0.01 \mathrm{M}-\mathrm{NaCl}$ solution. Elution was performed with $0.01 \mathrm{M}, 0.1 \mathrm{M}, 0.5 \mathrm{M}$ and $1 \mathrm{M}-\mathrm{NaCl}$ solution stepwisely at a flow rate of $2.5 \mathrm{~m} / / \mathrm{min}$. Fractions of $50 \mathrm{~m} l$ were collected and assayed for total carbohydrate $(-\bullet)$ and for protein $(0-0)$. and the second peak (polysaccharide B) was eluted with $0.01 \mathrm{M}-\mathrm{NaCl}$ solution. These peaks were separately passed through Sepharose $4 \mathrm{~B}$ columns and each was eluted as a single sharp peak (Figs. 3 and 4). The distribution constant $\left(K_{d}\right)$ values $^{31}$ of these purified polysaccharides were calculated by the Sepharose 4B gel-filtration analysis. The chromatograms suggested $K_{d}=0.90$ for polysaccharide A, and $K_{d}=0.79$ for polysaccharide B. It is assumed that the conformation of polysaccharide $A$ is less expanded than that of polysaccharide $B$.

The ultracentrifugal patterns of these polysaccharides indicated the presence of one com-

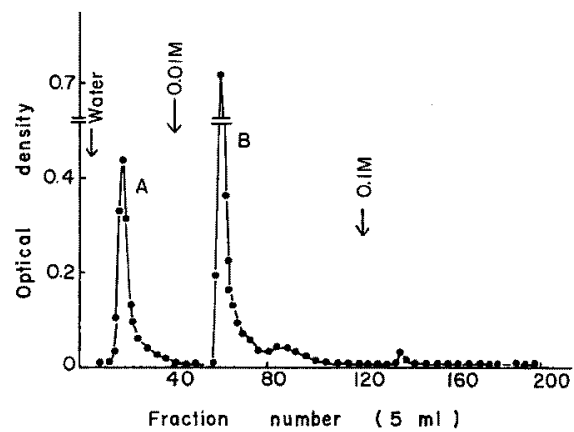

Fig. 2. DEAE-cellulose column chromatography of Fraction I.

Fraction I substance $(15.4 \mathrm{mg})$ was dissolved in $5 \mathrm{ml}$ of water and applied to a column (2.2X $27.5 \mathrm{~cm}$ ) of DEAE-cellulose $\left(\mathrm{OH}^{-}\right)$equilibrated with water. Elution was performed with water, $0.01 \mathrm{M}$ and $0.1 \mathrm{M}-\mathrm{NaCl}$ solutions stepwisely at a flow rate of $1.0 \mathrm{ml} / \mathrm{min}$. Fractions of $5 \mathrm{ml}$ were collected and assayed for total carbohydrate.

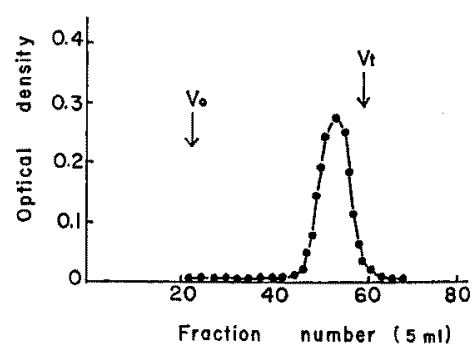

Fig. 3. Sepharose 4B column chromatography of polysaccharide $\mathbf{A}$.

Fraction A $(6.5 \mathrm{mg})$ in $2 \mathrm{ml}$ of $0.5 \mathrm{M}-\mathrm{NaCl}$ solution was applied to a column $(2.3 \times 90 \mathrm{~cm})$ of Sepharose $4 \mathrm{~B}$ and eluted with $0.5 \mathrm{M}-\mathrm{NaCl}$ solution at a flow rate of $5 \mathrm{~m} / / \mathrm{h}$. Fractions of $5 \mathrm{ml}$ were collected and assayed for total carbohydrate. 


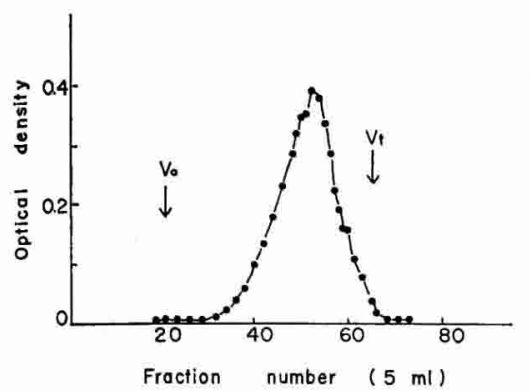

Fig. 4. Sepharose 4B column chromatography of polysaccharide $B$.

Fraction $B(8.0 \mathrm{mg})$ in $3 \mathrm{ml}$ of $0.5 \mathrm{M}-\mathrm{NaCl}$ solution was applied to a column of Sepharose $4 \mathrm{~B}(2.2 \times 87 \mathrm{~cm})$ and eluted with $0.5 \mathrm{M}-\mathrm{NaCl}$ solution at a flow rate of $9.1 \mathrm{~m} / / \mathrm{h}$. Fractions of $5 \mathrm{ml}$ were collected and assayed for total carbohydrate. ponent each other, and schlieren patterns of these polysaccharides showed symmetric peaks (Fig. 5). Approximate sedimentation coefficients were calculated by the standard method. ${ }^{4}$ The values were $1.96 \mathrm{~S}$ for polysaccharide $\mathrm{A}$ and $3.20 \mathrm{~S}$ for polysaccharide $\mathrm{B}$. This indicates that polysaccharide $\mathrm{A}$ is relatively low density as compared with polysaccharide B. The analytical data thus provide some support for proposal that polysaccharide $\mathrm{A}$ is relatively low molecular weight as compared with polysaccharide $\mathbf{B}$.

IR spectra of these polysaccharides are shown in Fig. 6. IR absorption bands between 750$900 \mathrm{~cm}^{-1}$ are useful for the analysis of glycosidic linkage of polysaccharide. IR spectra of these purified polysaccharide $\mathrm{A}$ and $\mathrm{B}$ likewise indicate the presence of $\beta$-linkages $\left(890 \mathrm{~cm}^{-1}\right)$ in these substances. IR absorption band at $1610 \mathrm{~cm}^{-1}$

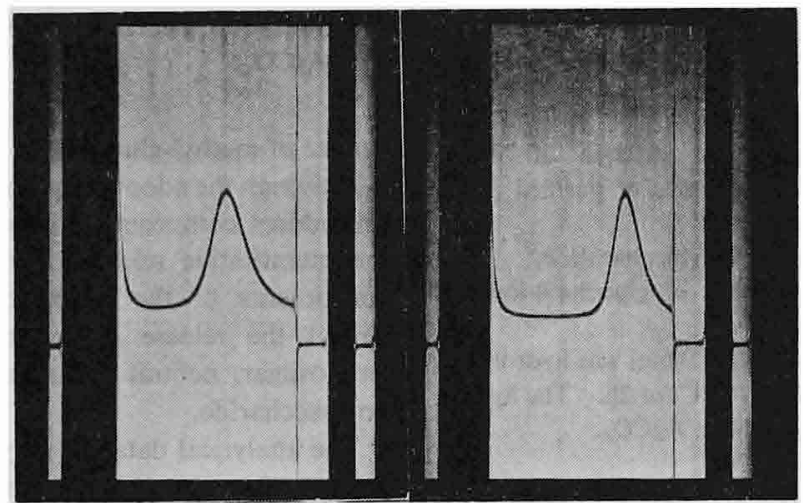

A $141 \mathrm{~min}, 70^{\circ}$ $96 \mathrm{~min}, 70^{\circ}$

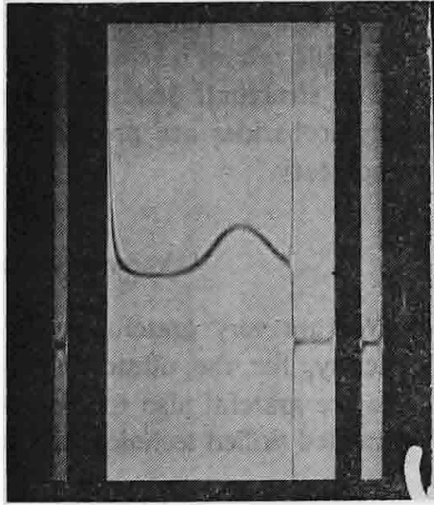

B $71 \mathrm{~min}, 55^{\circ}$

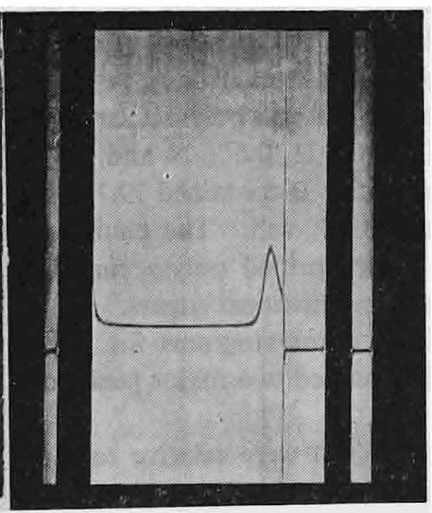

$15 \mathrm{~min}, 75^{\circ}$

Fig. 5. Ultracentrifugal patterns for purified polysaccharides.

Sedimentation patterns were obtained at various times after the rotor had reached at maximum speed of $60,000 \mathrm{rpm}$ at $25^{\circ} \mathrm{C}$ in $0.1 \mathrm{M}-\mathrm{NaCl}$ solution. Sedimentation is from right to left. The bar angles were indicated in the figure.

A Polysaccharide A; $37.0 \mathrm{mg} / \mathrm{ml}$.

B Polysaccharide B; $13.4 \mathrm{mg} / \mathrm{ml}$. 


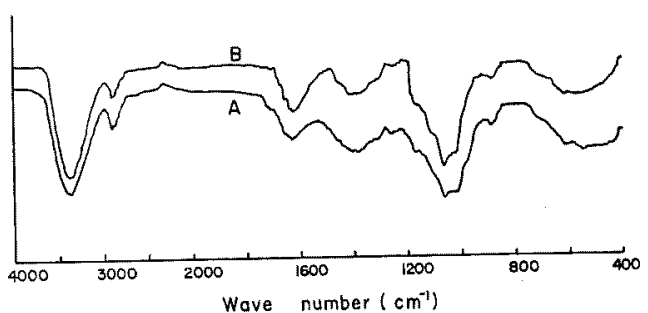

Fig. 6. Infrared spectra of purified polysaccharides. A Polysaccharide A, B Polysaccharide B.

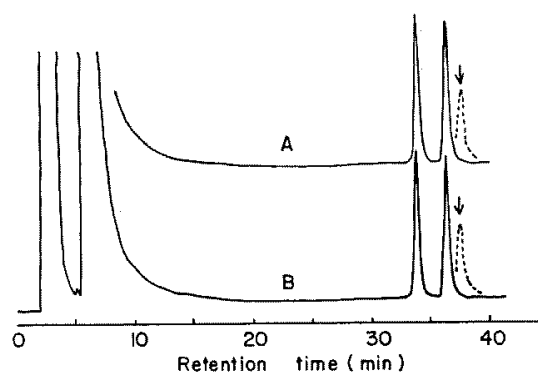

Fig. 7. Gas chromatographic patterns of TMSsugars from acid hydrolyzates of purified polysaccharides.

A Polysaccharide A, B Polysaccharide B.

Arrows indicate the peak of gluculono-lactone used as the reference.

Purified polysaccharide $(10.0 \mathrm{mg})$ was hydrolyzed with $2 \mathrm{~N}-\mathrm{HCl}(4 \mathrm{~m} /)$ at $100^{\circ} \mathrm{C}$ for $2 \mathrm{~h}$. The hydrolyzate was neutralyzed with $\mathrm{AgCO}_{3}$.

suggests the presence of carboxylate in both polysaccharides. The $\mathrm{C}=\mathrm{O}$ stretching band $(1725$ $\mathrm{cm}^{-1}$ ) was observed in polysaccharide $A$. This indicates the possibility of the presence of acetyl or other acyl groups in polysaccharide A.

Chemical analyses showed that polysaccharide $\mathrm{A}$ contained $39.4 \% \mathrm{C}, 5.6 \% \mathrm{H}, 0.6 \% \mathrm{~N}$ and $5.5 \%$ ash whereas polysaccharide $\mathrm{B}$ contained $39.7 \% \mathrm{C}$, $5.9 \% \mathrm{H}, 0.5 \% \mathrm{~N}$ and $4.6 \%$ ash. The analytical data indicate that these purified polysaccharides have no amino sugar as constituent sugars.

As shown in Fig. 7, chromatograms for polysaccharide A and B consisted two major peaks on acid hydrolysis.

The retention times (Rt) were relative to gluculonolactone used as the reference. The peaks with Rt 0.89 and Rt 0.97 are characteristics of $\alpha$ glucose and $\beta$-glucose respectively.

As shown in Fig. 8, one major and one minor peaks were detected on methanolysis. The major peak with Rt 0.93 is characteristic of methylglucoside. A minor peak is assumed to be the

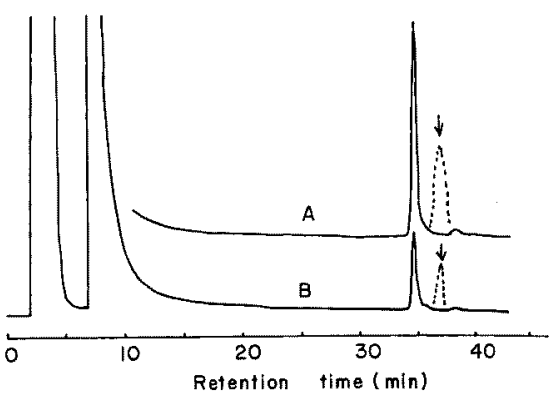

Fig. 8. Gas chromatographic patterns of TMSsugars from methanolyzates of purified polysaccharides.

A Polysaccharide A, B Polysaccharide B.

Arrows indicate the peak of gluculono-lactone used as the reference.

Purified polysaccharide $(10.0 \mathrm{mg})$ was methanolyzed with $5 \%$ methanol- $\mathrm{HCl}(4 \mathrm{ml})$ at $120^{\circ} \mathrm{C}$ for $1 \mathrm{~h}$. The methanolyzate was neutralyzed with $\mathrm{AgCO}_{8}$.

isomer of methyl-glucoside.

Although the adopted hydrolysis or methanolysis procedures compromise, which did not result in the quantitative release of various carbohydrate constituents of the polysaccharide, it seems to permit the release of monosaccharide such as aminosugar, neutral sugar and uronic acid from polysaccharide.

The analytical data for polysaccharide A and $B$ suggest that these polysaccharides contain only glucose residue. However, the possibility that these polysaccharides might contain subfractions other than sugars corresponding to side-chain materials cannot be eliminated.

The structural determinations of these purified polysaccharides are presently in progress in our laboratory.

\section{Acknowledgements}

We are very grateful to Dr. M. SATo of our Faculty, for the ultracentrifugal determinations. We are grateful also to Miss K. TaKaHAsH who provided skilled technical assistance.

\section{References}

1) K. OKutani and N. Morikawa: Bull. Japan. Soc. Sci. Fish., 44, 369-372 (1978).

2) K. Okutani: Bull. Japan. Soc. Sci. Fish., 42, 449-453 (1976). 
3) H. MORIYA: "Method for Gel-filtration", 7th ed., Hirokawa Publishing Co., Tokyo, 1973, pp. 1-7.

4) G. Matsumura: in "Method for Biochemical
Analysis" (ed. by Japanese Biochemical Society), Vol. 4, Tokyo Kagaku Dozin, Tokyo, 1976, pp. $448-460$. 